\title{
Adherence to Adjuvant Aromatase Inhibitor Therapy Among Postmenopausal Hispanic/Latino Women With Breast Cancer
}

\author{
ALEXANDER PHILIPOVSKIY ${ }^{1}$, ALELI CAMPBELL ${ }^{2}$, ROSALINDA HEYDARIAN $^{1}$, BRENDA CASTILLO $^{1}$, \\ ALOK K. DWIVEDI ${ }^{3}$, RICHARD MCCALLUM ${ }^{4}$, RENATO AGUILERA ${ }^{5}$, SUMIT GAUR $^{1}$ and NAHLEH ZEINA ${ }^{6}$ \\ ${ }^{1}$ Division of Hematology-Oncology, Department of Internal Medicine, \\ Texas Tech University Health Sciences Center, El Paso, TX, U.S.A.; \\ ${ }^{2}$ Department of Metallurgical, Materials and Biomedical Engineering, University of Texas, El Paso, TX, U.S.A.; \\ ${ }^{3}$ Division of Biostatistics \& Epidemiology, Department of Molecular and Translational Medicine, \\ Texas Tech University Health Sciences Center, Paul L. Foster School of Medicine, El Paso, TX, U.S.A.; \\ ${ }^{4}$ Division of Gastroenterology, Department of Internal Medicine, \\ Texas Tech University Health Sciences Center, Paul L. Foster School of Medicine, El Paso, TX, U.S.A.; \\ ${ }^{5}$ Department of Biological Sciences, University of Texas, El Paso, TX, U.S.A.; \\ ${ }^{6}$ Maroone Cancer Center Department of Hematology-Oncology, Cleveland Clinic Florida, Weston, FL, U.S.A.
}

\begin{abstract}
Aim: The purpose of this study was to determine the level of adherence to adjuvant aromatase inhibitor (AI) therapy and factors associated with non-adherence among Hispanic/Latino women with hormonal receptor-positive breast cancer $(B C)$ treated at an academic center at the American-Mexican border city of El Paso, TX. Patients and Methods: Institutional Review Board approval was obtained in this cross-sectional study using the validated Morisky Medication Adherence Scale to assess patient adherence to AI therapy. Patients diagnosed with stage I-III hormonal receptor-positive, human epidermal growth factor receptor 2-negative $B C$ who were on adjuvant AIs therapy were recruited from the Texas Tech University Health Sciences Center El Paso breast clinic. Results: Between September 2017 and August 2018, 122 consecutive patients were enrolled; 119 were analyzed, three were lost to follow up.

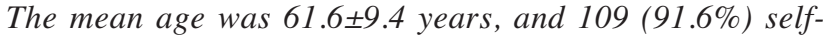
identified as Hispanic/Latino. A total of $58 \%$ reported an annual income of \$15,000 or less. Overall, 40.3\% had completed eighth grade or less education, $31.9 \%$ high school, and $12 \%$ had obtained a technical degree. The majority of patients (56\%) had either a medium (45\%) or a
\end{abstract}

This article is freely accessible online.

Correspondence to: Alexander Philipovskiy, MD, Ph.D. 4800 Alberta Ave., El Paso, TX, 79905, U.S.A. Tel: +1 9152154728, Fax: +19152158641, e-mail: alexander.philipovskiy@ttuhsc.edu

Key Words: Adjuvant aromatase inhibitor, breast cancer, postmenopausal, adherence. low level of adherence (11\%). High adherence was noted in $44 \%$ of participants. Seven (5.6\%) patients scored 2 or below on a 4-point scale for intentional adherence, and 18 (13.5\%) scored 2 or below on a 4-point scale for unintentional adherence. Conclusion: These data suggest that the majority of Hispanic/Latino women with breast cancer have medium or low levels of adherence to therapy with AIs. Factors associated with medium and low adherence were unintentional (forgetfulness), but also included intentional factors, such as avoidance of adverse effects and delays with obtaining refills (cost-related nonadherence).

Breast cancer (BC) is the second leading cause of cancer death after lung cancer in the United States (1). In 2018, the American Cancer Association estimated that there were 252,700 new cases of BC in the United States and 41,000 deaths from the disease (1). It is the major type of cancer among Hispanic/Latino women in the United States, with approximately 20,000 new cases and 3,000 deaths per year(2). From 2003 to 2018, the incidence rate of $\mathrm{BC}$ remained stable in both Hispanic and non-Hispanic White women (2). The use of screening mammography and advances in treatment modalities including the use of adjuvant endocrine therapy have contributed to the reduction of mortality from BC in the United States by approximately 24\% since 1990 (3). Multiple studies have shown substantial benefits from adjuvant endocrine therapy in improving progression-free and overall survival (4-7). For almost two decades, adjuvant endocrine therapy with an aromatase inhibitor (AI) has remained a gold-standard for patients with hormonal receptor-positive BC. In 2003, the first results of ATAC (arimidex, tamoxifen, alone or in combination) phase 
III clinical trial demonstrated a statistically significant advantage in disease-free survival among postmenopausal women initially taking anastrozole compared with tamoxifen as adjuvant therapy for hormonal receptor-positive local or locally advanced disease (6). Subsequent large clinical trials have confirmed the role of AI therapy in the management of postmenopausal women with $\mathrm{BC}$ and demonstrated a significant reduction of $30 \%$ in BC recurrence $(5,8-11)$. Despite the efficacy of AIs, it has been reported that the selfdiscontinuation rate is approaching $10 \%$ per year nationwide and that only $40-60 \%$ of women with BC complete 5 years of adjuvant endocrine therapy (12). There are multiple factors associated with self-discontinuation and nonadherence: cultural, limited insurance, lack of follow-up information, severity of adverse effects, older age or very young age, forgetfulness, trust in the physician and understanding of treatment recommendation. Early discontinuation can translate into a higher likelihood of relapse and shorter survival. A recent study of patients who were non-adherent (defined as omitting endocrine therapy for 180 days) showed an adjusted odds ratio for cancer recurrence of 2.88 compared to patients who did not adhere to therapy (13). Some studies have suggested a higher recurrence rate of $\mathrm{BC}$ among Hispanic/Latino women which might be at least partially related to early discontinuation or poor adherence rate to AI therapy (14-17). There is a paucity of studies assessing the adherence or discontinuation rate among Hispanic/Latino women and no prospective trial, to our knowledge, has addressed adherence to AI therapy among the Hispanic/Latino population.

The aim of this study was to assess the adherence rate to adjuvant endocrine therapy in patients seen at the Breast Care Center/Texas Tech University Health Sciences Center El Paso with estrogen receptor (ER)/progesterone receptor (PR)-positive BC living in the border City of El-Paso, Texas and to identify potential modifiable factors associated with AI non-adherence.

\section{Patients and Methods}

Patient population. This prospective (cross-sectional) study was approved by the Institutional Review Board of the Texas Tech University Health Sciences Center (TTUHSC), El Paso. The study population consisted predominantly from Hispanic/Latino (91.6\%) women living in the border city of El Paso, Texas and treated at TTUHSC, an academic medical center. To be eligible, women had to be diagnosed with stage I-III (with no evidence of metastatic disease, M0) histologically confirmed hormonal receptor-positive (ER/PR) invasive $\mathrm{BC}$ and be receiving adjuvant AI therapy (anastrozole, letrozole, or exemestane) for at least 1 month. Participants were to have completed all recommended local therapies (surgery, radiation if appropriate) and have recovered from all side-effects of chemotherapy, surgery, and radiation therapy. We excluded all male patients, patients with metastatic BC and premenopausal women who had not undergone menopause either surgically by oophorectomy or by hormonal ovarian ablation.

Patients were required to be able to complete a self-reported demographic questionnaire and the validated Morisky Medication Adherence Scale questionnaire (MMAS-8), in either English or Spanish [detailed MMAS-8 questionnaires can be found elsewhere $(18,19)]$. Self-reported medication adherence was measured by the MMAS-8 $(18,19)$. The MMAS- 8 scale consists of eight items, of which summation yields a maximum of 8 points. Level of adherence to AI therapy was categorized as high, medium, and low $(18,19)$.

The purpose of this study was to estimate the level of adherence to adjuvant AI therapy and the main factors associated with nonadherence among Hispanic/Latino women living in the border City of El-Paso, Texas, USA.

Pathological assessment. Pathological diagnosis, ER/PR status, and human epidermal growth factor receptor 2 (HER2)/neu status were determined by core biopsy during the initial evaluation before surgery. Standard immunohistochemical staining was used to determine hormonal receptor status. All tumors with more than $1 \%$ stained cells were considered to have a positive hormonal receptor status.

Statistical analysis. It has been shown in previous studies that the non-adherence rate to AIs range. From $20 \%$ to $75 \%(15,20-27)$. Assuming a non-adherence rate of $30 \%$ in our population, a sample size of 89 was sufficient to produce a two-sided $95 \%$ confidence interval (CI) with a width of $20 \%$ using a Z-test. Furthermore, this sample size was more than sufficient to evaluate at least five predictors for non-adherence using multiple logistic regression analysis with more than $80 \%$ power. The sample size estimation was carried out using PASS 14 (NCSS, LLC., Kaysville, UT, USA). The medium and low adherence rate to AI therapy ( $<8$ on MMAS- 8 ) was estimated along with $95 \%$ CI using a Z-test. Clinical and demographic cofactors were described using appropriate summary measures such as the mean or median, and standard deviation for quantitative data, while the frequency and proportion were used for categorical data. Furthermore, non-normal data was described using median and interquartile range. A logarithmic transformation was made to induce normality for non-Gaussian data. The frequency and cumulative frequency distribution of adherence rate was summarized. Chi-squared test and one-way ANOVA were used to compare the characteristics between non-adherent and adherent groups. The unadjusted and adjusted predictors of adherence levels were assessed using linear regression models and log Poisson regression models and reported as regression coefficients and odds ratio, 95\% CI and $p$-value. $p$-Values of less than 5\% were considered statistically significant. All the statistical analyses were conducted using STATA 14 (StataCorp LLC, College Station, TX USA) SAS 9.4 (SAS, Cary, NC, USA) and SPSS Statistics 25 (IBM, Armonk, NY, USA).

\section{Results}

Between 2017 and 2018, a total of 122 patients were enrolled. Of these, 119 consecutive postmenopausal women with hormonal receptor-positive $\mathrm{BC}$ were included in this analysis. Table I shows the summary clinical profile of patients. Of these, 85 (71.4\%) patients were born in Mexico, $31(26.1 \%)$ were from the USA, and the remaining three 
Table I. Clinical characteristics of the entire cohort, and by adherence levels $(n=119)$.

\begin{tabular}{|c|c|c|c|c|c|c|}
\hline \multirow[b]{2}{*}{ Factor } & & \multirow[b]{2}{*}{ Overall $(n=119)$} & \multicolumn{3}{|c|}{ MMAS-8 Adherence level } & \multirow[b]{2}{*}{$p$-Value } \\
\hline & & & High $(\mathrm{n}=52)$ & Medium $(n=54)$ & Low $(n=13)$ & \\
\hline Age, years & Mean \pm SD & $61.6(9.4)$ & $62.7(9.5)$ & $61.8(9.4)$ & $56.8(8.5)$ & 0.14 \\
\hline \multirow[t]{3}{*}{ Age group, n (\%) } & $<60$ Years & $50(42.0 \%)$ & $18(36)$ & $23(46)$ & $9(18)$ & 0.076 \\
\hline & $\geq 60$ Years & $68(57.1 \%)$ & $34(50)$ & $30(44.12)$ & $4(5.88)$ & \\
\hline & Unknown & $1(0.8 \%)$ & & & & \\
\hline Years since diagnosis & Mean \pm SD & $6.5(3.8)$ & $6.2(3.9)$ & $6.5(3.6)$ & $7.4(3.7)$ & 0.61 \\
\hline MMAS-8 score & Mean \pm SD & $7.0(1.2)$ & $8.0(0.0)$ & $6.6(0.5)$ & $4.8(1.2)$ & $<0.001$ \\
\hline \multirow[t]{3}{*}{ Duration of AI Tx } & $<5$ Years & $43(36.1 \%)$ & $23(53.49)$ & $15(34.88)$ & $5(11.63)$ & 0.28 \\
\hline & $\geq 5$ Years & $74(62.2 \%)$ & $29(39.19)$ & $37(50)$ & $8(10.81)$ & \\
\hline & Unknown & $2(1.7 \%)$ & $0(0)$ & $2(100)$ & $0(0)$ & \\
\hline \multirow[t]{4}{*}{ Breast cancer stage, n (\%) } & 1 & $42(35.3 \%)$ & $19(45.24)$ & $18(42.86)$ & $5(11.9)$ & 0.96 \\
\hline & 2 & $48(40.3 \%)$ & $20(41.67)$ & $23(47.92)$ & $5(10.42)$ & \\
\hline & 3 & $27(22.7 \%)$ & $13(48.15)$ & $12(44.44)$ & $2(7.41)$ & \\
\hline & Unknown & $2(1.7 \%)$ & & & & \\
\hline \multirow[t]{3}{*}{ Education level, n (\%) } & $>8$ th Grade & $48(40.3 \%)$ & $20(41.67)$ & $21(43.75)$ & $7(14.58)$ & 0.54 \\
\hline & $\mathrm{HS} / \mathrm{GED}$ & $38(31.9 \%)$ & $20(52.63)$ & $15(39.47)$ & $3(7.89)$ & \\
\hline & Higher education & $33(27.7 \%)$ & $12(36.36)$ & $18(54.55)$ & $3(9.09)$ & \\
\hline \multirow[t]{2}{*}{ Marital status, n (\%) } & Married & $52(43.7 \%)$ & $26(50)$ & $21(40.38)$ & $5(9.62)$ & 0.47 \\
\hline & Other & $67(56.3 \%)$ & $26(38.81)$ & $33(49.25)$ & $8(11.94)$ & \\
\hline \multirow[t]{3}{*}{ Income, n (\%) } & $\geq \$ 15,000$ & $49(41.2 \%)$ & $21(42.86)$ & $24(48.98)$ & $4(8.16)$ & 0.62 \\
\hline & $<\$ 15,000$ & $69(58.0 \%)$ & $31(44.93)$ & $29(42.03)$ & $9(13.04)$ & \\
\hline & Unknown & $1(0.8 \%)$ & & & & \\
\hline \multirow[t]{3}{*}{ Parity, n (\%) } & Multiparous & $98(82.4 \%)$ & $40(40.82)$ & $46(46.94)$ & $12(12.24)$ & 0.003 \\
\hline & Nulliparous & $11(9.2 \%)$ & $10(90.91)$ & $0(0)$ & $1(9.09)$ & \\
\hline & Single & $10(8.4 \%)$ & $2(20)$ & $8(80)$ & $0(0)$ & \\
\hline \multirow[t]{2}{*}{ Surgery, n (\%) } & No & $7(5.9 \%)$ & $4(57.14)$ & $2(28.57)$ & $1(14.29)$ & 0.65 \\
\hline & Yes & $112(94.1 \%)$ & $48(42.86)$ & $52(46.43)$ & $12(10.71)$ & \\
\hline \multirow[t]{2}{*}{ Radiation, n (\%) } & No & $25(21.0 \%)$ & $9(36)$ & $12(48)$ & $4(16)$ & 0.54 \\
\hline & Yes & $94(79.0 \%)$ & $43(45.74)$ & $42(44.68)$ & $9(9.57)$ & \\
\hline \multirow[t]{4}{*}{ Smoking status, n (\%) } & Former & $26(21.8 \%)$ & $9(34.62)$ & $13(50)$ & $4(15.38)$ & 0.73 \\
\hline & No & $86(72.3 \%)$ & $41(47.67)$ & $37(43.02)$ & $8(9.3)$ & \\
\hline & Yes & $6(5.0 \%)$ & $2(33.33)$ & $3(50)$ & $1(16.67)$ & \\
\hline & Unknown & $1(0.8 \%)$ & $0(0 \%)$ & $1(2 \%)$ & $0(0 \%)$ & \\
\hline
\end{tabular}

AI Tx: Aromatase inhibitor therapy; HS/GED: high school diploma/General Educational Development certificate; MMAS-8: Morisky Medication Adherence Scale-8; SD: standard deviation. Use of the CMMAS is protected by US copyright laws. Permission for use is required. A license agreement is available from: Donald E. Morisky, 14725 NE 20th St Bellevue, WA 98007, USA; dmoriskiy@gmail.com or trubow1@gmail.com.

$(2.5 \%)$ were classified as being from other nations (Philippines, Germany, and Nicaragua). The mean age of the patients was $61.6 \pm 9.4$ years. A total of $109(91.6 \%)$ identified themselves as Hispanic/Latino, and 10 (8.4\%) as other [Caucasian, African American (AA), Asian and unknown]. Overall, 58\% $(n=69)$ of patients were of low socioeconomic status, $40 \%(n=48)$ had attended elementary or middle school ( $\leq 8^{\text {th }}$ grade $), 32 \%(n=32)$ had obtained a high school diploma or General Educational Development certificate), and $28 \%(n=33)$ had pursued a higher education.

The average MMAS- 8 score was estimated as $7 \pm 1.2$ (range $=1-8)$. Overall, low/medium adherence rate of AI was estimated as $56 \%$ (95\% CI=47-65\%). Patients were divided into three groups according to adherence level: High, medium, and low, in an attempt to determine factors associated with inferior (medium and low) adherence. The medium and high adherence categories had higher numbers of participants, whereas the number in the low adherence group was smaller. We identified that a medium level and high level of adherence to AI was quite common among our patients, with $11 \%$ reporting a low level of adherence, $45 \%(n=54)$ reporting a medium adherence, and $44 \%$ reporting a high level of adherence. The intentional and unintentional subcategories of the adherence MMAS- 8 model were also evaluated. The rate of intentional low/medium adherence was $26 \%(n=31)$, while the unintentional rate was $51 \%(n=61)$. In total, 25 patients had low adherence for both unintentional and intentional reasons. The answers identifying reasons for not taking their cancer therapy included: sideeffects, forgetfulness, too expensive, and other reasons; forgetfulness was the highest $(63 \%, \mathrm{n}=75)$, delays in refills $(5 \%$, $\mathrm{n}=6)$, AEs $(5 \%, \mathrm{n}=6)$ and lack of insurance $(3 \%, \mathrm{n}=4)$. Some of the reasons listed for intentional low adherence were 
Table II. Unadjusted association between cofactors and high adherence level compared to low/medium adherence level.

\begin{tabular}{|c|c|c|c|c|c|}
\hline \multirow[b]{2}{*}{ Factor } & & \multicolumn{2}{|c|}{ Adherence level } & \multirow[b]{2}{*}{ OR $(95 \% \mathrm{CI})$} & \multirow[b]{2}{*}{$p$-Value } \\
\hline & & High $(n=52)$ & Low/medium $(\mathrm{n}=67)$ & & \\
\hline Years since diagnosis & Mean \pm SD & $6.2(3.9)$ & $6.6(3.6)$ & $0.97(0.88-1.07)$ & 0.53 \\
\hline \multirow[t]{3}{*}{ Age group, $\mathrm{n}(\%)$} & $<60$ Years & $18(35 \%)$ & $32(48 \%)$ & Reference & \\
\hline & $\geq 60$ Years & $34(65 \%)$ & $34(51 \%)$ & $1.78(0.84-3.76)$ & 0.13 \\
\hline & Unknown & $0(0 \%)$ & $1(1 \%)$ & & \\
\hline \multirow[t]{3}{*}{ Duration of AI Tx } & $<5$ Years & $23(44 \%)$ & $20(30 \%)$ & Reference & \\
\hline & $\geq 5$ Years & $29(56 \%)$ & $45(67 \%)$ & $0.56(0.26-1.2)$ & 0.14 \\
\hline & Unknown & $0(0 \%)$ & $2(3 \%)$ & & \\
\hline \multirow[t]{4}{*}{ Breast cancer stage, $\mathrm{n}(\%)$} & 1 & $19(37 \%)$ & $23(34 \%)$ & Reference & \\
\hline & 2 & $20(38 \%)$ & $28(42 \%)$ & $0.86(0.37-1.99)$ & 0.73 \\
\hline & 3 & $13(25 \%)$ & $14(21 \%)$ & $1.12(0.43-2.96)$ & 0.81 \\
\hline & Unknown & $0(0 \%)$ & $2(3 \%)$ & & \\
\hline \multirow[t]{3}{*}{ Education level, n (\%) } & $>8$ th Grade & $20(38 \%)$ & $28(42 \%)$ & Reference & \\
\hline & HS/GED & $20(38 \%)$ & $18(27 \%)$ & $1.56(0.66-3.67)$ & 0.31 \\
\hline & Higher education & $12(23 \%)$ & $21(31 \%)$ & $0.8(0.32-1.99)$ & 0.63 \\
\hline \multirow[t]{2}{*}{ Marital status, n (\%) } & Married & $26(50 \%)$ & $26(39 \%)$ & Reference & \\
\hline & Other & $26(50 \%)$ & $41(61 \%)$ & $0.63(0.3-1.32)$ & 0.22 \\
\hline \multirow[t]{3}{*}{ Income, n (\%) } & $\geq \$ 15,000$ & $21(40 \%)$ & $28(42 \%)$ & Reference & \\
\hline & $<\$ 15,000$ & $31(60 \%)$ & $38(57 \%)$ & $1.09(0.52-2.28)$ & 0.82 \\
\hline & Unknown & $0(0 \%)$ & $1(1 \%)$ & & \\
\hline \multirow[t]{3}{*}{ Parity, n (\%) } & Multiparous & $40(77 \%)$ & $58(87 \%)$ & Reference & \\
\hline & Nulliparous & $10(19 \%)$ & $1(1 \%)$ & $14.5(1.79-117.79)$ & 0.012 \\
\hline & Single & $2(4 \%)$ & $8(12 \%)$ & $0.36(0.07-1.8)$ & 0.21 \\
\hline \multirow[t]{2}{*}{ Surgery, n (\%) } & No & $4(8 \%)$ & $3(4 \%)$ & Reference & \\
\hline & Yes & $48(92 \%)$ & $64(96 \%)$ & $0.56(0.12-2.63)$ & 0.47 \\
\hline \multirow[t]{2}{*}{ Radiation, n (\%) } & No & $9(17 \%)$ & $16(24 \%)$ & Reference & \\
\hline & Yes & $43(83 \%)$ & $51(76 \%)$ & $1.5(0.6-3.73)$ & 0.38 \\
\hline \multirow[t]{4}{*}{ Smoking status, n (\%) } & Former & $9(17 \%)$ & $17(25 \%)$ & Reference & \\
\hline & No & $41(79 \%)$ & $45(67 \%)$ & $1.72(0.69-4.28)$ & 0.24 \\
\hline & Yes & $2(4 \%)$ & $4(6 \%)$ & $0.94(0.14-6.19)$ & 0.95 \\
\hline & Unknown & $0(0 \%)$ & $1(1 \%)$ & & \\
\hline
\end{tabular}

AI Tx: Aromatase inhibitor therapy; CI: Confidence interval; HS/GED: high school diploma/General Educational Development certificate; OR: odds ratio; SD: standard deviation. Use of the CMMAS is protected by US copyright laws. Permission for use is required. A license agreement is available from: Donald E. Morisky, 14725 NE 20th St Bellevue, WA 98007, USA; dmoriskiy@ gmail.com or trubow1@gmail.com.

withholding all medications due to other health procedures, lack of insurance and tiredness. Reasons for unintentional low adherence were forgetfulness, and lack of insurance.

Table I also shows clinical characteristics of patients according to adherence level. Among all considered cofactors, the distribution of age of patients, duration of AI treatment, and parity status were found to be different across different adherence levels. Younger age, greater than 5 years of duration of AI, and multiparity seem to be associated with a low or medium adherence level.

A summary of overall adherence with respect to variables measured and age is provided in Table II using a one-way ANOVA to evaluate adherence based on two age groups ( $<60$ and $\geq 60$ years); there was a statistically significant mean age difference of $0.5(p=0.04)$ between these groups. Table II shows the unadjusted association of cofactors with a high adherence level compared to combined low or medium adherence. This analysis further suggested that older age, less duration of AI treatment, and nulliparity tended to be associated with a high adherence level. The actual mean age of the low adherence group was lower than that of the other two groups (medium and high adherence). The difference was not statistically significant; however, it is worth noting that the mean age for the low adherence group was 57 years, while that for the high adherence group was 62 years. Results from a multinomial logistic regression analysis indicate that the age group below 60 years of age was 4.25 times more likely to exhibit low adherence to AI therapy compared to the older group ( $\geq 60$ years) $(p=0.03)$. Furthermore, the $<60$ years age group was also 1.4 times more likely to have medium adherence compared to the older group ( $p=0.357)$.

In the adjusted analyses, only older age and a nulliparous status were more likely to be associated with a high (Table III) as well as medium (Table IV) adherence level after adjusting for education status. 
Table III. Adjusted associations of factors with high adherence level.

\begin{tabular}{lccc}
\hline Factor & OR & $95 \% \mathrm{CI}$ & $p$-Value \\
\hline Age & & & \\
$\quad<60$ Years & Reference & - & - \\
$\geq 60$ Years & 2.03 & $0.88-4.65$ & 0.095 \\
Parity & & & \\
$\quad$ Multiparous & Reference & - & - \\
Nulliparous & 23.88 & $2.61-218.09$ & 0.005 \\
Single & 0.39 & $0.07-2.07$ & 0.272 \\
Education level & & & - \\
$>8^{\text {th }}$ Grade & Reference & - & 0.137 \\
HS/GED & 2.02 & $0.80-5.10$ & 0.319 \\
Higher education & 0.58 & $0.20-1.68$ & 0 \\
\hline
\end{tabular}

CI: Confidence interval; HS/GED-high school diploma/General Educational Development certificate; OR: odds ratio.

Other demographic factors such as marital status, education and income level were also evaluated in Table III. No significant associations were observed, all ORs were $<1$ (results not shown).

BC stage was not associated with medium and high adherence which was very similar among the three BC stages, whereas for low adherence, the relatively smaller group size across all cancer stages preclude any conclusion.

\section{Discussion}

This cross-sectional study suggests a high non-adherence rate to adjuvant AI and indicates that the majority of women surveyed $(56 \%)$ reported medium or low adherence to this vital treatment. Non-adherence to adjuvant endocrine therapy is a complex and multifactorial problem that can substantially alter the outcome of medical treatment and has been associated with an increase in BC relapse, additional physician visits, higher hospitalization rates, and shorter survival $(21,28-30)$. Identifying modifiable causes of nonadherence is an important priority and needs to be promptly addressed $(11,31)$. Our findings indicate that the majority of the participants surveyed had medium or low compliance with adjuvant endocrine therapy, which is a particularly concern in the current era of trends towards minimally effective treatments, and more reliance on adjuvant endocrine therapy as opposed to previously overtreating patients with adjuvant chemotherapy. This was the result of the introduction of genomic analyses into standard care for early-stage ER/PR-positive and HER2-neu-negative BC, reducing the use of chemotherapy significantly (32). Therefore, adherence to adjuvant endocrine therapy is now ever more important for patients with $\mathrm{BC}$ who may rely on this treatment as the sole systemic treatment modality due to the recent evolution of modern care.
In this study we identified three main reasons for nonadherence: Forgetfulness, adverse events, and delays with getting refills (cost-related non-adherence). While forgetfulness is a quite common form of unintentional nonadherence, based on retrospective and prospective memory failure (33), we feel that this is a potentially modifiable factor, especially in view of high degree of forgetfulness in elderly patients ( $>50 \%$ of our patient population). Interventions to address this problem may include implementing simple measures such as cueing, chaining (associating new and established behaviors), use of social support and ancillary clinical services (family members, nurses, pharmacists), and electronic monitoring devices. For patients with a cellular device, the option to add a reminder in their calendar could be recommended by their care specialists. Physicians can help by simplifying seniors' complex medical regimens (using once-daily dosing) and discontinuing unnecessary medications. Assessment of the usefulness of a text message reminder to patients to continue their endocrine therapy is currently being studied in a randomized controlled trial (SWOG 1105/NCT01515800). Some studies have suggested more frequent follow-up visits and follow-up with specialists rather than general practitioners might have a positive impact on adherence (27). An interesting observation in our study was that patient parity was positively associated with adherence. Multiparous women were more likely to be highly adherent compared to nulliparous ones. At this point, we do not have explanations for this finding.

Reasons for non-adherence have been previously studied (17, 34-37). Multiple studies have evaluated factors correlated with non-adherence to endocrine adjuvant therapy $(28,34)$. Most commonly reported factors associated with non-adherence were sociodemographic factors (patient age, race and ethnicity), treatment-related factors (type of breast surgery, side-effects of chemotherapy), cost-related factors low income, defined by Medicaid as adults with incomes up to $138 \%$ the Federal Poverty Level of $\$ 29,435$ per year for a family of three and $\$ 17,236$ per year for an individual in 2019, as well as beliefs about the benefits and risks of endocrine therapy $(20,28,34,37,38)$.

There are limited data in modern literature addressing adherence to adjuvant endocrine therapy among women of racial/ethnical minority groups. In one retrospective, crosssectional study, Gerber et al. analyzed 450 Medicare cases of patients on adjuvant endocrine therapy. They identified a statistically significant difference in adherence to endocrine therapy between African Americans (AA) and Non-Hispanic White women. More AAs reported not following their physician's instruction on how to take medications and reported early self-discontinuation (16). Another study demonstrated poor level of adherence in both AA and Hispanic/Latino women. AA and Hispanic/Latino women 
Table IV. Adjusted associations of factors with high and medium adherence levels.

\begin{tabular}{|c|c|c|c|c|c|c|c|}
\hline \multirow[b]{2}{*}{ Factor } & & \multicolumn{3}{|c|}{ High vs. Low } & \multicolumn{3}{|c|}{ Medium $v s$. Low } \\
\hline & & OR & $95 \% \mathrm{CI}$ & $p$-Value & OR & $95 \% \mathrm{CI}$ & $p$-Value \\
\hline \multirow[t]{2}{*}{ Age } & $<60$ Years & Reference & - & - & - & - & - \\
\hline & $\geq 60$ Years & 5.18 & $1.34-19.95$ & 0.017 & 3.27 & $0.87-12.20$ & 0.078 \\
\hline \multirow[t]{2}{*}{ Parity } & Multiparous & Reference & - & - & - & - & - \\
\hline & Nulliparous/single & 4.61 & $0.49-43.20$ & 0.18 & 2.19 & $0.23-20.64$ & 0.495 \\
\hline \multirow[t]{3}{*}{ Education level } & $>8$ th Grade & Reference & - & - & - & - & - \\
\hline & $\mathrm{HS} / \mathrm{GED}$ & 2.67 & $0.57-12.60$ & 0.213 & 1.75 & $0.37-8.19$ & 0.478 \\
\hline & Higher education & 1.20 & $0.24-6.08$ & 0.827 & 1.92 & $0.41-9.08$ & 0.409 \\
\hline
\end{tabular}

CI: Confidence interval; HS/GED-high school diploma/General Educational Development certificate; OR: odds ratio.

were more likely than non-Hispanic Whites to report costrelated non-adherence $(35.1 \%, 36.5 \%$ and $26.7 \%$, respectively, $\mathrm{p}<0.001)$ (17). However, these studies were somewhat inconsistent, and the methodology used to gather data was not standardized, which can lead to incomplete conclusions. Our data showed slightly lower non-adherence rates compared to national and international published nonadherence data $(22,23,25,26,34,36,39)$. The strengths of our analysis include the licensing and utilization of the validated 8-item MMAS-8 adherence questionnaire as described previously $(18,19,40,41)$. In addition, the average duration of adjuvant endocrine therapy was 4.3 years, which allowed for assessment of long-term adherence to therapy. Previous studies using self-reported adherence to tamoxifen or AI therapy have found that approximately $15 \%$ to $35 \%$ of women discontinue their therapy prematurely at varying lengths of follow-up $(26,34,39)$. A large retrospective study in Ireland using insurance claims-based methodology reported that $22 \%$ of women had discontinued tamoxifen by the end of the first year of adjuvant therapy, and by 3.5 years, 35\% had discontinued therapy (28). Hershman et al. retrospectively analyzed adherence of 8,769 patients with early stage $\mathrm{BC}$ to adjuvant endocrine therapy (tamoxifen and AI). At 4.5 years of treatment, 32\% of patient had self-discontinued adjuvant endocrine therapy. Additionally, women younger than 40 years of age had the highest rate of discontinuation (hazard ratio $=1.51: 95 \%$ $\mathrm{CI}=1.23-1.85)(15)$.

Our study had several limitations. The cross-sectional design did not allow for the assessment of changes in adherence over time. However, it provided what we believe to be a good representation of adherence rates in a large cohort of Hispanic/Latino patients (91.6\%), as well as information regarding some potential factors which affect adherence in this minority population which could be useful to improve adherence rates in this population. The study population was possibly limited by selection bias as patients with the poorest adherence to therapy may not attend their clinical follow-up, and therefore may not have been captured by this study. Moreover, patient self-reported adherence rates might overestimate real-world adherence when compared to actual prescription fill rates, as shown in some studies $(16,17,23)$.

In conclusion, these data suggest a low level of adherence to adjuvant endocrine therapy in the Hispanic-Latino women with BC. Factors associated with non-adherence included forgetfulness, adverse effects, and delay with obtaining refills due to cost. Appropriate education and frequent assessment of adherence and management of side-effects, combined with close monitoring with $\mathrm{BC}$ specialists, might help improve endocrine therapy adherence in all women with early-stage BC, including Hispanic/Latino women and other minorities

\section{Funding}

Texas Tech University Medical Sciences Center. Department of Internal Medicine. Seed Founding program 2017-2018.

\section{Conflicts of Interest}

Alexander Philipovskiy declares that he has no conflict of interest. Aleli Campbell declares that she has no conflict of interest. Dwivedi Kumar Alok declares that he has no conflict of interest. Brenda Castillo declares that she has no conflict of interest. Heydarian Rosalinda. declares that she has no conflict of interest. Richard McCallum declares that he has no conflict of interest in medical oncology. Renato Aguilera declares that he has no conflict of interest in medical oncology. Sumit Guar declares that he has no conflict of interest. Nahleh Zeina declares that she has no conflict of interest.

\section{Authors' Contributions}

AP conceived the study and prepared the draft of the article. AC participated in drafting the article and study conception. RH participated in drafting the article and approved the article. AKD performed statistical analysis and participated in drafting the article. 
RM participated in drafting the article and approved the article. RA participated in drafting and final revision of the article and approved the article. SG participated in the design of the study and approved the article. NZ conceived the study and approved the article.

\section{Acknowledgements}

The Authors would like to acknowledge Sean Connery, Christopher Dodo, Krysta Lin and Zeinab Abdularhman for their efforts in article preparation. We thank Professor Donald E. Morisky, Department of Community Health Sciences, UCLA Fielding School of Public Health, Los Angeles, United States, for granting us the use of the copyrighted MMAS-8. Professor Morisky has worked his entire career in developing the very important instrument for medication-taking behavior measure. Use of the CMMAS is protected by US copyright laws. Permission for use is required. A license agreement is available from: Donald E. Morisky, $14725 \mathrm{NE}$ 20th St Bellevue, WA 98007, USA; dmoriskiy@gmail.com.

\section{References}

1 Siegel RL, Miller KD and Jemal A: Cancer statistics, 2018. CA Cancer J Clin 68(1): 7-30, 2018. PMID: 29313949. DOI: $10.3322 /$ caac. 21442

2 Miller KD, Goding Sauer A, Ortiz AP, Fedewa SA, Pinheiro PS, Tortolero-Luna G, Martinez-Tyson D, Jemal A and Siegel RL: Cancer statistics for hispanics/latinos, 2018. CA Cancer J Clin, 2018. PMID: 30285281. DOI: 10.3322/caac.21494

3 Parkin DM, Bray FI and Devesa SS: Cancer burden in the year 2000. The global picture. Eur J Cancer 37(Suppl 8): S4-66, 2001. PMID: 11602373.

4 Mouridsen HT and Robert NJ: The role of aromatase inhibitors as adjuvant therapy for early breast cancer in postmenopausal women. Eur J Cancer 41(12): 1678-1689, 2005. PMID: 16098456. DOI: 10.1016/j.ejca.2004.10.020

5 Crivellari D, Sun Z, Coates AS, Price KN, Thurlimann B, Mouridsen H, Mauriac L, Forbes JF, Paridaens RJ, CastiglioneGertsch M, Gelber RD, Colleoni M, Lang I, Del Mastro L, Gladieff L, Rabaglio M, Smith IE, Chirgwin JH and Goldhirsch A: Letrozole compared with tamoxifen for elderly patients with endocrine-responsive early breast cancer: The big 1-98 trial. J Clin Oncol 26(12): 1972-1979, 2008. PMID: 18332471. DOI: 10.1200/JCO.2007.14.0459

6 Eastell R, Adams JE, Coleman RE, Howell A, Hannon RA, Cuzick J, Mackey JR, Beckmann MW and Clack G: Effect of anastrozole on bone mineral density: 5-year results from the anastrozole, tamoxifen, alone or in combination trial 18233230 J Clin Oncol 26(7): 1051-1057, 2008. PMID: 18309940. DOI: 10.1200/JCO.2007.11.0726

7 Goss PE, Ingle JN, Pritchard KI, Ellis MJ, Sledge GW, Budd GT, Rabaglio M, Ansari RH, Johnson DB, Tozer R, D'Souza DP, Chalchal H, Spadafora S, Stearns V, Perez EA, Liedke PE, Lang I, Elliott C, Gelmon KA, Chapman JA and Shepherd LE: Exemestane versus anastrozole in postmenopausal women with early breast cancer: Ncic ctg ma.27--a randomized controlled phase iii trial. J Clin Oncol 31(11): 1398-1404, 2013. PMID: 23358971. DOI: 10.1200/JCO.2012.44.7805

8 Goss PE, Ingle JN, Martino S, Robert NJ, Muss HB, Piccart MJ, Castiglione M, Tu D, Shepherd LE, Pritchard KI, Livingston RB, Davidson NE, Norton L, Perez EA, Abrams JS, Therasse P,
Palmer MJ and Pater JL: A randomized trial of letrozole in postmenopausal women after five years of tamoxifen therapy for early-stage breast cancer. N Engl J Med 349(19): 1793-1802, 2003. PMID: 14551341. DOI: 10.1056/NEJMoa032312

9 Coombes RC, Hall E, Gibson LJ, Paridaens R, Jassem J, Delozier T, Jones SE, Alvarez I, Bertelli G, Ortmann O, Coates AS, Bajetta E, Dodwell D, Coleman RE, Fallowfield LJ, Mickiewicz E, Andersen J, Lonning PE, Cocconi G, Stewart A, Stuart N, Snowdon CF, Carpentieri M, Massimini G, Bliss JM, van de Velde $\mathrm{C}$ and Intergroup Exemestane $\mathrm{S}$ : A randomized trial of exemestane after two to three years of tamoxifen therapy in postmenopausal women with primary breast cancer. $\mathrm{N}$ Engl $\mathrm{J}$ Med 350(11): 1081-1092, 2004. PMID: 15014181. DOI: 10.1056/NEJMoa040331

10 Coates AS, Keshaviah A, Thurlimann B, Mouridsen H, Mauriac L, Forbes JF, Paridaens R, Castiglione-Gertsch M, Gelber RD, Colleoni M, Lang I, Del Mastro L, Smith I, Chirgwin J, Nogaret JM, Pienkowski T, Wardley A, Jakobsen EH, Price KN and Goldhirsch A: Five years of letrozole compared with tamoxifen as initial adjuvant therapy for postmenopausal women with endocrine-responsive early breast cancer: Update of study big 198. J Clin Oncol 25(5): 486-492, 2007. PMID: 17200148. DOI: 10.1200/JCO.2006.08.8617

11 Cuzick J, Sestak I, Baum M, Buzdar A, Howell A, Dowsett M and Forbes JF: Effect of anastrozole and tamoxifen as adjuvant treatment for early-stage breast cancer: 10-year analysis of the atac trial. The Lancet Oncology 11(12): 1135-1141, 2010. DOI: 10.1016/S1470-2045(10)70257-6

12 Nekhlyudov L, Li L, Ross-Degnan D and Wagner AK: Five-year patterns of adjuvant hormonal therapy use, persistence, and adherence among insured women with early-stage breast cancer. Breast Cancer Res Treat 130(2): 681-689, 2011. PMID: 21842245. DOI: $10.1007 / \mathrm{s} 10549-011-1703-\mathrm{Z}$

13 Barron TI, Cahir C, Sharp L and Bennett K: A nested casecontrol study of adjuvant hormonal therapy persistence and compliance, and early breast cancer recurrence in women with stage i-iii breast cancer. Br J Cancer 109(6): 1513-1521, 2013. PMID: 24002590. DOI: 10.1038/bjc.2013.518

14 Hershman DL, Shao T, Kushi LH, Buono D, Tsai WY, Fehrenbacher L, Kwan M, Gomez SL and Neugut AI: Early discontinuation and non-adherence to adjuvant hormonal therapy are associated with increased mortality in women with breast cancer. Breast Cancer Res Treat 126(2): 529-537, 2011. PMID: 20803066. DOI: $10.1007 / \mathrm{s} 10549-010-1132-4$

15 Hershman DL, Kushi LH, Shao T, Buono D, Kershenbaum A, Tsai WY, Fehrenbacher L, Gomez SL, Miles S and Neugut AI: Early discontinuation and nonadherence to adjuvant hormonal therapy in a cohort of 8,769 early-stage breast cancer patients. J Clin Oncol 28(27): 4120-4128, 2010. PMID: 20803066. DOI: $10.1007 / \mathrm{s} 10549-010-1132-4$

16 Gerber BS, Cho YI, Arozullah AM and Lee SY: Racial differences in medication adherence: A cross-sectional study of medicare enrollees. Am J Geriatr Pharmacother 8(2): 136-145, 2010. PMID: 20439063. DOI: 10.1016/j.amjopharm.2010.03.002

17 Gellad WF, Haas JS and Safran DG: Race/ethnicity and nonadherence to prescription medications among seniors: Results of a national study. J Gen Intern Med 22(11): 1572-1578, 2007. PMID: 17882499. DOI: 10.1007/s11606-007-0385-z

18 Morisky DE, Ang A, Krousel-Wood M and Ward HJ: Predictive validity of a medication adherence measure in an outpatient 
setting. J Clin Hypertens (Greenwich) 10(5): 348-354, 2008. PMID: 18453793. DOI: 10.1111/j.1751-7176.2008.07572.x

19 Morisky DE, Green LW and Levine DM: Concurrent and predictive validity of a self-reported measure of medication adherence. Med Care 24(1): 67-74, 1986. PMID: 3945130. DOI: 10.1097/00005650-198601000-00007

20 Atkins L and Fallowfield L: Intentional and non-intentional nonadherence to medication amongst breast cancer patients. Eur J Cancer 42(14): 2271-2276, 2006. PMID: 16644208. DOI: 10.1016/j.ejca.2006.03.004

21 Hsieh KP, Chen LC, Cheung KL, Chang CS and Yang YH: Interruption and non-adherence to long-term adjuvant hormone therapy is associated with adverse survival outcome of breast cancer women--an asian population-based study. PLoS One 9(2): e87027, 2014. PMID: 24586261. DOI: 10.1371/journal.pone.0087027

22 Ruddy K, Mayer E and Partridge A: Patient adherence and persistence with oral anticancer treatment. CA Cancer J Clin 59(1): 56-66, 2009. PMID: 19147869. DOI: 10.3322/caac.20004

23 Kesmodel SB, Goloubeva OG, Rosenblatt PY, Heiss B, Bellavance EC, Chumsri S, Bao T, Thompson J, Nightingale G, Tait NS, Nichols EM, Feigenberg SJ and Tkaczuk KH: Patientreported adherence to adjuvant aromatase inhibitor therapy using the morisky medication adherence scale: An evaluation of predictors. Am J Clin Oncol 41(5): 508-512, 2018. PMID: 27322700. DOI: $10.1097 / C O C .0000000000000314$

$24 \mathrm{He}$ W, Fang F, Varnum C, Eriksson M, Hall P and Czene K: Predictors of discontinuation of adjuvant hormone therapy in patients with breast cancer. J Clin Oncol 33(20): 2262-2269, 2015. PMID: 26033800. DOI: 10.1200/JCO.2014.59.3673

25 Wigertz A, Ahlgren J, Holmqvist M, Fornander T, Adolfsson J, Lindman $\mathrm{H}$, Bergkvist $\mathrm{L}$ and Lambe $\mathrm{M}$ : Adherence and discontinuation of adjuvant hormonal therapy in breast cancer patients: A population-based study. Breast Cancer Res Treat 133(1): 367-373, 2012. PMID: 22286315. DOI: 10.1007/s10549012-1961-4

26 Partridge AH, LaFountain A, Mayer E, Taylor BS, Winer E and Asnis-Alibozek A: Adherence to initial adjuvant anastrozole therapy among women with early-stage breast cancer. J Clin Oncol 26(4): 556-562, 2008. PMID: 18180462. DOI: 10.1200/ JCO.2007.11.5451

27 Simon R, Latreille J, Matte C, Desjardins P and Bergeron E: Adherence to adjuvant endocrine therapy in estrogen receptorpositive breast cancer patients with regular follow-up. Can J Surg 57(1): 26-32, 2014. PMID: 24461223. DOI: 10.1503/cjs.006211

28 Barron TI, Connolly R, Bennett K, Feely J and Kennedy MJ: Early discontinuation of tamoxifen: A lesson for oncologists. Cancer 109(5): 832-839, 2007. PMID: 17243168. DOI: $10.1002 /$ cncr. 22485

29 Jankowitz RC and Davidson NE: Adjuvant endocrine therapy for breast cancer: How long is long enough? Oncology (Williston Park) 27(12): 1210-1216, 1224, 2013. PMID: 17243168. DOI: $10.1002 /$ cncr.22485

30 McCowan C, Shearer J, Donnan PT, Dewar JA, Crilly M, Thompson AM and Fahey TP: Cohort study examining tamoxifen adherence and its relationship to mortality in women with breast cancer. Br J Cancer 99(11): 1763-1768, 2008. PMID: 18985046. DOI: $10.1038 /$ sj.bjc. 6604758

31 Baum M, Budzar AU, Cuzick J, Forbes J, Houghton JH, Klijn JG, Sahmoud T and Group AT: Anastrozole alone or in combination with tamoxifen versus tamoxifen alone for adjuvant treatment of postmenopausal women with early breast cancer: First results of the atac randomised trial. Lancet 359(9324): 2131-2139, 2002. PMID: 12090977.

32 Sparano JA, Gray RJ, Makower DF, Pritchard KI, Albain KS, Hayes DF, Geyer CE, Jr., Dees EC, Goetz MP, Olson JA, Jr., Lively T, Badve SS, Saphner TJ, Wagner LI, Whelan TJ, Ellis MJ, Paik S, Wood WC, Ravdin PM, Keane MM, Gomez Moreno HL, Reddy PS, Goggins TF, Mayer IA, Brufsky AM, Toppmeyer DL, Kaklamani VG, Berenberg JL, Abrams J and Sledge GW, Jr.: Adjuvant chemotherapy guided by a 21 -gene expression assay in breast cancer. N Engl J Med 379(2): 111-121, 2018. PMID: 29860917. DOI: 10.1056/NEJMoa1804710

33 Murray MD, Morrow DG, Weiner M, Clark DO, Tu W, Deer MM, Brater DC and Weinberger M: A conceptual framework to study medication adherence in older adults. Am J Geriatr Pharmacother 2(1): 36-43, 2004. PMID: 15555477. DOI: 10.1016/s1543-5946(04)90005-0

34 Partridge AH, Wang PS, Winer EP and Avorn J: Nonadherence to adjuvant tamoxifen therapy in women with primary breast cancer. J Clin Oncol 21(4): 602-606, 2003. PMID: 12586795. DOI: $10.1200 / \mathrm{JCO} .2003 .07 .071$

35 Neugut AI, Zhong X, Wright JD, Accordino M, Yang J and Hershman DL: Nonadherence to medications for chronic conditions and nonadherence to adjuvant hormonal therapy in women with breast cancer. JAMA Oncol 2(10): 1326-1332, 2016. PMID: 27281650. DOI: 10.1001/jamaoncol.2016.1291

36 Yang J, Neugut AI, Wright JD, Accordino M and Hershman DL: Nonadherence to oral medications for chronic conditions in breast cancer survivors. J Oncol Pract 12(8): e800-809, 2016. PMID: 27407167. DOI: 10.1200/JOP.2016.011742

37 Bright EE, Petrie KJ, Partridge AH and Stanton AL: Barriers to and facilitative processes of endocrine therapy adherence among women with breast cancer. Breast Cancer Res Treat 158(2): 243251, 2016. PMID: 27342455. DOI: 10.1007/s10549-016-3871-3

38 Martin LR, Williams SL, Haskard KB and Dimatteo MR: The challenge of patient adherence. Ther Clin Risk Manag 1(3): 189199, 2005. PMID: 18360559.

39 Lash TL, Fox MP, Westrup JL, Fink AK and Silliman RA: Adherence to tamoxifen over the five-year course. Breast Cancer Res Treat 99(2): 215-220, 2006. PMID: 16541307. DOI: 10.1007/s10549-006-9193-0

40 Krousel-Wood MA, Islam T, Webber LS, Re RS, Morisky DE and Muntner P: New medication adherence scale versus pharmacy fill rates in seniors with hypertension. Am J Manag Care 15(1): 59-66, 2009. PMID: 19146365.

41 Morisky DE and DiMatteo MR: Improving the measurement of self-reported medication nonadherence: Final response. J Clin Epidemiol 64(3): 258-263, 2011. PMID: 21144706. DOI: 10.1016/j.jclinepi.2010.09.002 